\title{
Geometric linewidth and the impact of thermal processing on the stress regimes induced by electroless copper metallization for Si integrated circuit interconnect technology
}

\author{
P. J. McNally a) and J. Kanatharana \\ Microelectronics Group, Research Institute for Networks \& Communications Engineering (RINCE), \\ School of Electronic Engineering, Dublin City University, Dublin 9, Ireland \\ B. H. W. Toh and D. W. McNeill \\ School of Electronic \& Electrical Engineering, Queens University of Belfast, Belfast BT9 5AH, \\ United Kingdom
}

A. N. Danilewsky

Kristallographisches Institut, Universität Freiburg, Hebelstrasse 25, D-79104 Freiburg, Germany

T. Tuomi, L. Knuuttila, J. Riikonen, and J. Toivonen

Optoelectronics Laboratory, Helsinki University of Technology, PO Box 3500, 02015 TKK,

Helsinki, Finland

\author{
R. Simon \\ Topo-beamline, Institut für Synchrotronstrahlung (ISS), Forschungszentrum Karlsruhe GmbH, \\ Postfach 3640, D-76021 Karlsruhe, Germany
}

(Received 28 June 2004; accepted 8 September 2004)

\begin{abstract}
Mechanical strains and stresses are a major concern in the development of copper-based on-chip metallization. Synchrotron x-ray topography (SXRT), micro-Raman spectroscopy, finite element modeling (FEM), and atomic force microscopy (AFM) have been used to examine the strain fields imposed by electroless $\mathrm{Cu}$ metallization on the underlying $\mathrm{Si}$. As expected, we have observed enhanced strain regions close to the metal line edges. These strain fields tend to zero at annealing temperatures approaching $200{ }^{\circ} \mathrm{C}$, and thereafter the magnitudes of the strain fields at $300{ }^{\circ} \mathrm{C}$ and $400{ }^{\circ} \mathrm{C}$ are much higher, implying a return to a higher strain regime. Although the strain transition point is slightly different from the SXRT result, the FEM results confirm the existence of a zero-strain transition point as a function of thermal anneal. We have also examined the generated stress in $\mathrm{Si}$ as a function of $\mathrm{Cu}$ linewidth $L$. We have found that the stress $\sigma_{X X}$ due to the electroless copper metallization is empirically related to the $\mathrm{Cu}$ linewidth in terms of an exponential distribution. For $\mathrm{Cu}$ linewidths less than $20 \mu \mathrm{m}$, the stress magnitudes increased with decreasing $\mathrm{Cu}$ linewidth due to the thermal stress in the absence of self-annealing, whereas the stress decreased with increasing linewidths in the range of $60-100 \mu \mathrm{m}$ due to a relief of the thermal stress possibly via the self-annealing effect. This self-annealing phenomenon was observed using AFM. It is observed that the stresses in the Si shifted to a compressive state after annealing at $400{ }^{\circ} \mathrm{C}$. (C) 2004 American Institute of Physics. [DOI: 10.1063/1.1811780]
\end{abstract}

\section{INTRODUCTION}

Copper is the leading on-chip interconnect metal for many integrated circuit (IC) applications due to the circuit speed advantage resulting from the higher electrical conductivity of $\mathrm{Cu}$ as compared to Al. The resistance-capacitance time constant associated with interconnect delays can be reduced by using a metal with a low resistivity and an interlevel dielectric (ILD) with a low dielectric constant. ${ }^{1}$ Copper has the second lowest resistivity of any nonsuperconductor, $\rho=1.69-1.77 \times 10^{-6} \Omega \mathrm{cm}$ at $18-20^{\circ} \mathrm{C}^{2}$ However, it has been found that the appearance of stress and defects/ dislocations in copper metallization increases the resistivity. ${ }^{3}$ Dislocations tend to invoke electron scattering at the surface, resulting in an increase of the metal resistivity. Stress induces

\footnotetext{
${ }^{a)}$ Author to whom correspondence should be addressed; FAX: +353-17005508; Electronic mail: patrick.mcnally@ rince.ie
}

a phonon-electron scattering condition in the crystal lattice, which is different from the unstrained lattice and increases the resistivity. ${ }^{4}$

Mechanical strains and stresses are a major concern in IC processing. They have a large effect on the manufacturing reliability and the properties of devices. Besser ${ }^{5}$ compared the mechanical stress obtained in $\mathrm{Al}$ and $\mathrm{Cu}$ interconnect lines of $0.18 \mu \mathrm{m}$ logic technology using the x-ray diffraction technique. It was found that the mechanical stresses of dual damascene patterns with ILD layers were much smaller in the $\mathrm{Cu}(286 \mathrm{MPa})$ than $\mathrm{Al}(411 \mathrm{MPa})$ because stressinduced voiding may be less prevalent in $\mathrm{Cu}$ lines. This result is similar to Kasthurirangan et al. ${ }^{6}$ Sullivan ${ }^{7}$ noted that the stresses in $\mathrm{Cu}$ metallization with a low- $k$ dielectric ILD layer were much smaller than those with the higher- $k$ silicon dioxide dielectric, primarily because of lower thermal conductivity and lower mechanical strength of the aforementioned low- $k$ material. 


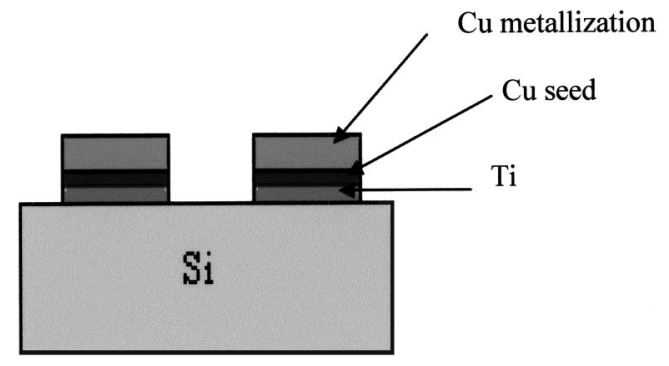

FIG. 1. A schematic outline of the electroless $\mathrm{Cu}$ deposition process.

The aim of this study is to ascertain the nature of $\mathrm{Cu}$ interconnect strains imposed on the underlying $\mathrm{Si}$ substrates for a typical electroless deposition technology. These strains were analyzed for varying $\mathrm{Cu}$ interconnect linewidths and were studied using the complementary techniques of microRaman spectroscopy ( $\mu \mathrm{RS})$, synchrotron x-ray topography (SXRT), finite element modeling (FEM) ${ }^{8,9}$ and atomic force microscopy (AFM).

\section{EXPERIMENTAL DETAILS}

Electroless deposited $\mathrm{Cu}$ lines were patterned by a photolithographic lift-off process. The process steps are illustrated in Fig. 1. At the outset, a $100 \pm 10 \mathrm{~nm}$ thick Ti barrier layer was deposited using a dc magnetron sputtering method. An Argon carrier gas pressure of $3.5 \times 10^{-3}$ mbar with a dc power of $350 \mathrm{~V} \times 0.8 \mathrm{~A}(320 \mathrm{~W})$ were used for the Ti deposition. Without breaking the vacuum, a $20 \mathrm{~nm} \mathrm{Cu}$ seed layer was deposited on the samples. This seed was then used for subsequent electroless $\mathrm{Cu}$ deposition.

Nine $\mathrm{Cu}$ lines 100,60,40,20,10,8, 6, 4, and $2 \mu \mathrm{m}$ geometrical width were deposited along the [110] direction of the $\mathrm{Si}$ (001) substrate. The spacing between these lines was typically $150-200 \mu \mathrm{m}$. (001) surface orientation $p$-doped Si wafers were used in these experiments. The electroless $\mathrm{Cu}$ metallization samples were deposited based on the recipe from Shacham-Diamand..$^{10} \mathrm{Cu}$ deposition is possible in an alkaline solution; therefore common chemicals such as sodium hydroxide $\mathrm{NaOH}$ and potassium cyanide are often added to increase the $p \mathrm{H}$ of the solution. However, sodium and potassium ions can accumulate in silicon dioxide, resulting in changes to its electrical properties. It is known that the sodium concentration must be limited to be less than $10^{9} \mathrm{~cm}^{-2}$. Many researchers have found that tetra-methylammonium-hydroxide (TMAH) is the best alternative for $\mathrm{Cu}$ metallization in VLSI/ULSI technology. Following Ref. 10, TMAH was used to adjust the $p \mathrm{H}$ level of the solution to $12.3-12.7$, and the temperature was adjusted to a range of 75-80 ${ }^{\circ} \mathrm{C}$. The electroless $\mathrm{Cu}$ deposition solution components are shown in Table I. The deposition rate was $\approx 40 \mathrm{~nm} / \mathrm{min}$ and the $\mathrm{Cu}$ electroless metal was grown to a thickness of $500 \mathrm{~nm}$.

The synchrotron $\mathrm{x}$-ray topography measurements were performed at ANKA, Institut für Synchrotronstrahlung (ISS), Karlsruhe, Germany, and HASYLAB-DESY, Hamburg, Germany (Hamburger Synchrotronstrahlungslabor am Deutschen Elektronen-Synchrotron) utilizing white beam synchrotron radiation. The rings operated at energies of $2.5 \mathrm{GeV}$
TABLE I. Electroless $\mathrm{Cu}$ deposition components and functions.

\begin{tabular}{lcc}
\hline \hline \multicolumn{1}{c}{ Components } & Function & Quantity (in range) \\
\hline $\mathrm{CuSO}_{4} \cdot 5 \mathrm{H}_{2} \mathrm{O}$ & Provides $\mathrm{Cu}(\mathrm{II})$ ions & $(0.05-0.1) M$ \\
$2,2^{\prime}$-dipyridyl & Stablizer & $(0.5-1.0) M$ \\
EDTA & Complexing agent & $(0.1) M$ \\
$\mathrm{HCHO}$ & Reducing agent & $(0.01-0.1) M$ \\
Triton ${ }^{\circledR} \mathrm{x}-100$ & Surfactant & $0.5 \%-2 \%$ \\
\hline \hline
\end{tabular}

and $4.45 \mathrm{GeV}$, respectively, and at typical beam currents of 100-200 mA. The standard Laue or Bragg pattern of topographs ${ }^{11}$ was recorded on Geola/Slavich holographic high-resolution (grain size $\sim 40 \mathrm{~nm}$ ) VRP-M films, or lower ( $\sim 1 \mu \mathrm{m}$ grain size) Kodak SR-45 Professional x-ray film. The distance from the sample to the film was $50 \mathrm{~mm}$ for all samples. The samples were set parallel to the film for the large area back reflection (LA-BRT) or back reflection section (BRST) geometries and the beam was collimated by slits to a size of $\sim 20 \mu \mathrm{m} \times 1.5 \mathrm{~mm}$ for the section arrangement. ${ }^{8,9}$ The samples were turned $180^{\circ}$ and tilted $18^{\circ}$ to perform the section transmission (ST) experiments. ${ }^{11}$ All samples were examined at room temperature. The back reflection topographs were generated by the 228 harmonic reflection with a penetration depth $t_{\mathrm{p}}$ of $65.7 \mu \mathrm{m}$. The ST images were generated by the 111 reflection. Magnified images of the $\mathrm{x}$-ray topographs have been captured from the original $\mathrm{x}$-ray films using a system comprising of a microscope with a charge-coupled device (CCD) camera, frame grabber, and appropriate software.

Geometrical resolution is governed by the synchrotron beam divergence. It is given by $\delta=H L / D$, where $H$ is the radiation source dimension, $L$ is the source-sample distance, and $D$ is the sample-film distance ${ }^{12}$ and usually lies in the $1-2 \mu \mathrm{m}$ range at the beamlines used in this study. Since Tuomi et al. introduced synchrotron x-ray topography with high-resolution results in $1974,{ }^{11}$ many scientists have used SXRT to investigate crystalline defect structure. Subsequently, the theoretical basis for the contrast mechanisms has been elucidated by e.g. Authier et al. ${ }^{13}$ Blech and Meieran have explained the extinction and anomalous contrast phenomena in x-ray topography images for strained $\mathrm{Si}$ during device processing. ${ }^{14-17}$ In a later work, McNally et al. ${ }^{18}$ provided evidence that strain magnitudes as low as $|\varepsilon|=6$ $\times 10^{-5}$ could be easily imaged using SXRT. These strain levels correspond to equivalent $\mathrm{Si}$ minimum observable stress magnitudes of $|\sigma|_{\min } \sim 10 \mathrm{MPa}$.

Micro-Raman spectroscopic analysis was performed on a Jobin-Yvon LabRam800 system, used in backscattering configuration in which only the longitudinal optical modes are activated for both the substrate and the epitaxial layers. A $488 \mathrm{~nm} \mathrm{Ar}^{+}$laser with a spot size of $1 \mu \mathrm{m}$ which probes right through to the Si substrate was used and the different positions on each sample were scanned for $5 \mathrm{~min}$ each. Longer scans (of $15 \mathrm{~min}$ ) were also carried out for control purposes. An automatic $X-Y$ stage with a minimum movement of $0.1 \mu \mathrm{m}$ was used to move the sample during the measurements. A plasma line at $560 \mathrm{~cm}^{-1}$ was used as an internal calibration of the measurements to eliminate envi- 


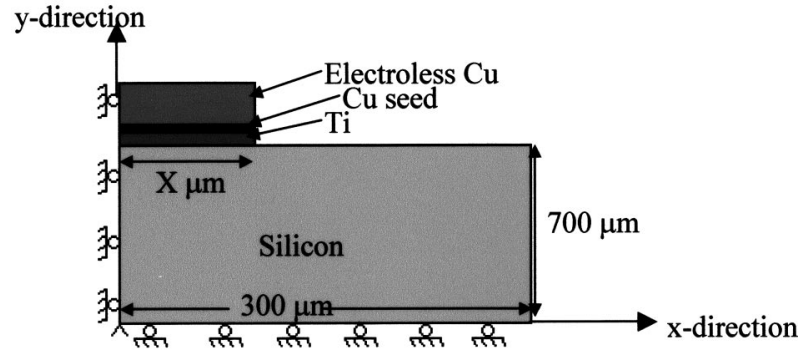

FIG. 2. Typical FEM geometry and model boundary conditions for the metallized sample.

ronmental and CCD temperature fluctuations during the experiments. The spatial strain distribution in the Si sample can be examined from the measured frequencies of Raman peaks compared with those of a strain-free reference Si sample at $521 \mathrm{~cm}^{-1}$. The relationship between Raman shift and linear strain was derived by De Wolf ${ }^{19}$ and is given by

$$
\sigma_{X X}(\mathrm{MPa})=-434 \Delta \omega\left(\mathrm{cm}^{-1}\right)
$$

where $\sigma_{X X}=$ the uniaxial stress in MPa and $\Delta \omega=$ the Raman shift between the measured Raman peak of strained $\mathrm{Si}\left(\omega_{j}\right)$ compared with that of strain-free $\operatorname{Si}\left(\omega_{0}\right), \Delta \omega=\omega_{j}-\omega_{0}, \omega_{j}$ $=$ the measured frequency of the silicon Raman peak and $\omega_{0}=$ the frequency of the silicon Raman in the stress-free state.

In this study, the experiments were performed by pointing the laser along the $\mathrm{Si}[001]$ direction with the $\mathrm{Cu}$ lines running along the [110] direction and measuring the strains along the [110] direction. Using appropriate curve-fitting software on this high-resolution $\mu \mathrm{RS}$ system, shifts in the $\mathrm{Si}$ Raman phonon peak position as low as $0.04 \mathrm{~cm}^{-1}$ can be reliably detected. Using Eq. (1) above, this corresponds to an uncertainty in measured stress values of $\sim 17.5 \mathrm{MPa}$. This value of $17.5 \mathrm{MPa}$ is also the lowest detectable magnitude of stress.

The FEM technique is used to compare the influence of linewidths on the electroless $\mathrm{Cu}$ metallization and to compare with the SXRT and $\mu$ RS results. For speed and ease of simulation, two-dimensional (2D) plane strain finite element models have been employed in these experiments. The geometry, dimensions, and boundary conditions of the metallized samples are illustrated in Fig. 2. The metallization with linewidths of $0.1,0.5,1.0,2.0,5.0,10,20,40,60$, and $100 \mu \mathrm{m}$ were simulated using FEM; therefore the dimension $X$ in Fig. 2 is actually the half-width of the line. This ensured a useful spread of data points across the experimental data range and in between the experimental data points as well. Approximately 100000 nodes were used to achieve the simulation. The finite element analyses were carried out using Quickfield ${ }^{\circledR}$ Professional version 4.2. ${ }^{20}$ The materials considered in these models are the $\mathrm{Si}$ substrate, the Ti barrier layer, and $\mathrm{Cu}$. These materials are assumed to be isotropic and linearly elastic. Their physical properties are given in Table II.

Finally, AFM analysis was performed using a Pacific
TABLE II. Materials properties for finite element analysis (Refs. 1, 5, 6, 8, 9, and 22).

\begin{tabular}{lccc}
\hline \hline Materials & $\begin{array}{c}\text { Young's modulus } \\
\left(\mathrm{E} \times 10^{9}\right) \mathrm{N} / \mathrm{m}^{2}\end{array}$ & $\begin{array}{c}\text { Poisson's ratio } \\
(\nu)\end{array}$ & $\begin{array}{c}\text { Coefficient of thermal } \\
\text { expansion }\left(\alpha, \times 10^{-6}\right) /{ }^{\circ} \mathrm{C}\end{array}$ \\
\hline $\mathrm{Si}$ & 112.4 & 0.28 & 2.5 \\
$\mathrm{Ti}$ & 116.0 & 0.34 & 8.9 \\
$\mathrm{Cu}$ & 123.0 & 0.33 & 17.0 \\
\hline \hline
\end{tabular}

Nanotechnology Series 2002 AFM system. A contact mode with a $2 \mathrm{~Hz}$ scan rate and $2.15 \mu \mathrm{m} \times 2.15 \mu \mathrm{m}$ sampling area were employed in this experiment.

\section{RESULTS AND DISCUSSION}

\section{A. Geometric linewidth dependence of the strain in $\mathrm{Si}$ induced by the electroless $\mathrm{Cu}$ metallization process}

The very strong contrast near the metal line edges in the BRST of Fig. 3 confirms the dependence of the strain fields with varying electroless $\mathrm{Cu}$ linewidths. This topograph shows the very typical black and white contrast (extinction contrast) within the highly strained $\mathrm{Si}$ substrate near the edges of the metal lines, which are due to the imposed strain fields in the diffracting Si (Ref. 15)—see Arrows j. A rough estimation of the stress/strain imposed on $\mathrm{Si}$ for electroless $\mathrm{Cu}$ deposition is based on a calculation of the thermal stress due to the large difference in CTE (coefficient of thermal expansion) since the temperature of the deposition solution was $\sim 80^{\circ} \mathrm{C}$ during the $\mathrm{Cu}$ deposition. The calculation of the maximum value of stress for a uniform film when the behavior is purely elastic is given by

$$
\sigma_{\max }=\Delta \alpha E \Delta T /(1-v),
$$

where $\sigma_{\max }=$ the maximum generated thermal stress, $\Delta \alpha$ $=$ the difference of $\mathrm{CTE}$ between $\mathrm{Si}$ and $\mathrm{Cu} \approx 13.6 \mathrm{ppm} /{ }^{\circ} \mathrm{C}$, $E=$ Young's modulus $\approx 162.3 \mathrm{GPa}$, and $\nu=$ Poisson's ratio $=0.28{ }^{21}$ Using Eq. (2), the estimation of maximum stress is of the order of $100 \mathrm{MPa}$. It must be emphasized that this is only a rough qualitative estimate. A more complete analysis would have to include the crystallographic anisotropy of $\mathrm{Si}$ together with the interaction of the anisotropic elastic properties of $\mathrm{Cu}$. To confirm this, the authors performed a number of x-ray diffraction experiments (XRD) on the electroless $\mathrm{Cu}$ both before and after annealing. The XRD measurements

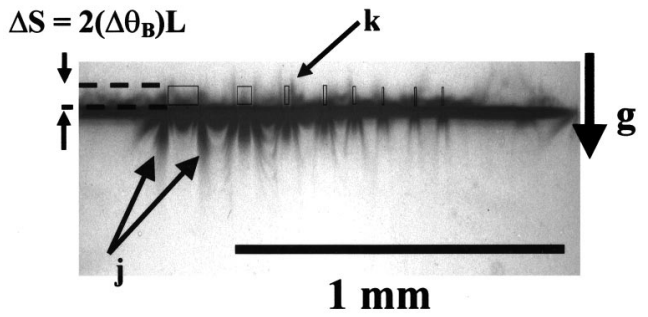

FIG. 3. $\overline{22} 8 \mathrm{BRST}$ of wafer with $500 \mathrm{~nm}$ thick electroless $\mathrm{Cu}$ metallization, $20 \mathrm{~nm} \mathrm{Cu}$ seed, $100 \mathrm{~nm} \mathrm{Ti}$ on Si using lift-off pattern. The positions of the $\mathrm{Cu}$ lines of widths $100,60,40,20,10,8,6$, and $4 \mu \mathrm{m}$, left to right, respectively, are indicated. The projection of the diffraction vector $\mathbf{g}$ on the recording film is also shown. 


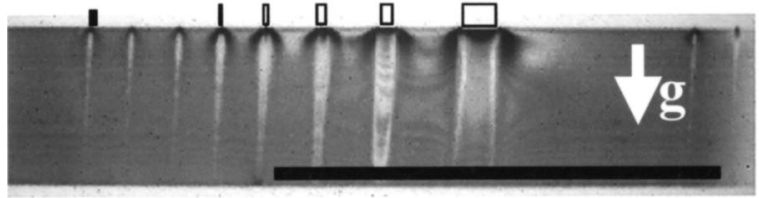

$1 \mathrm{~mm}$

FIG. 4. $111 \mathrm{ST}$ image of same sample as per Fig. 3. The position of the $\mathrm{Cu}$ lines of widths $100,60,40,20,10$, and $4 \mu \mathrm{m}$, right to left, respectively, are indicated. The projection of the diffraction vector $\mathbf{g}$ on the recording film is also shown.

were performed using a Philips X'Pert PRO XRD system with a model PW3040 (mppc) X-ray generator and a model PW3050/65 goniometer. The XRD patterns were compared with standard patterns from the Powder Diffraction File Release 2000, Data Sets 1-50 plus 70-88, International Centers for Diffraction data. The data confirmed that the $\mathrm{Cu}$ electroless plating technique created $\mathrm{Cu}$ predominantly orientated along $\langle 111\rangle$ and $\langle 220\rangle$ planes in almost equal quantities. Due to this multiple texturing, it was felt that a simplistic firstorder estimation of induced stresses, based on an isotropic model was justified.

In addition to the extinction contrast, the severely strained $\mathrm{Si}$ near the edge of $\mathrm{Cu}$ lines also appears via the orientational contrast mechanism in the $\overline{228}$ BRST of Fig. 3. The orientational contrast is observed as a lifting of the image of highly strained Si near the line edges above the image of the rest of the Si (Arrow k). The orientational contrast can be observed if this misorientation exceeds the x-ray beam divergence $\Delta \phi$, which is equal to $0.238 \mathrm{mrad}$ for beamline F-1 in HASYLAB, and represents the worst case limit in these experiments. The height of the orientational contrast shift is $\Delta S=2\left(\Delta \theta_{\mathrm{B}}\right) L$, where $\Delta \theta$ is the effective misorientation, $L$ is the distance between sample and film $(50 \mathrm{~mm}$ in this case). This can yield quantitative estimates for the magnitude of strain in the underlying silicon as described, in that $\Delta \theta_{\mathrm{B}} \cong \gamma_{x y}{ }^{8}$. In the case of the $100 \mu \mathrm{m}$ wide $\mathrm{Cu}$ line, $\Delta S$ $\approx 0.05 \mathrm{~mm}$, therefore, $\Delta \theta_{\mathrm{B}} \cong \gamma_{x y} \cong 5 \times 10^{-4}$ or $0.05 \%$. This implies that the magnitudes of shear stresses are given by $\left|\tau_{x y}\right|=G\left|\gamma_{x y}\right|$, where $G=$ shear modulus $=162 \mathrm{GPa}^{21}$ Thus, the limit on the stress magnitudes is of the order of $\left|\tau_{x y}\right|$ $\approx 81 \mathrm{MPa}$. In the case of the $20 \mu \mathrm{m}$ wide $\mathrm{Cu}$ line, $\Delta S$ $\approx 0.08 \mathrm{~mm}, \Delta \theta_{\mathrm{B}} \cong \gamma_{x y} \cong 8 \times 10^{-4}$ or $0.08 \%$. Thus, $\left|\tau_{x y}\right|$ $\approx 130 \mathrm{MPa}$. These are both of the same order of magnitude as the stresses estimated using Eq. (2).

From both the calculation and experiments, the orientational contrast shows that the stress near the $\mathrm{Cu}$ line edge increases with decreasing $\mathrm{Cu}$ linewidth. The relationship between the $\mathrm{Cu}$ linewidth and the stresses near the line edge can be clarified using FEM, which will be described in a later section. A ST image of the same region of the sample (Fig. 4) illustrates severe destruction of the Pendellösung fringes, which implies high strain fields in the $\mathrm{Si}$ crystal. Some orientational contrast is visible in this image. However, the misorientation is too difficult to measure reliably in this case. The strain fields may fall in magnitude with increasing $\mathrm{Cu}$ linewidth, but interestingly, the spatial extent of

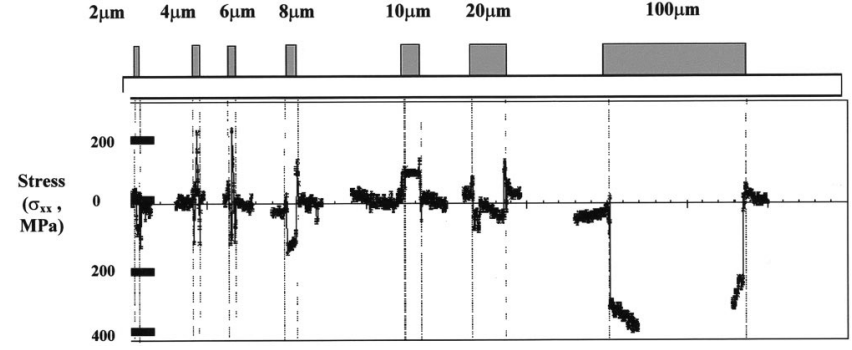

FIG. 5. The normal stress (indicated by $S_{X X}$ ) in the Si substrate just below the $\mathrm{Si} /$ metal interface due to the $500 \mathrm{~nm}$ thick electroless $\mathrm{Cu}$ metallization as a function of $\mathrm{Cu}$ linewidths, as measured using $\mu \mathrm{RS}$. Pre annealed sample. The locations of the $\mathrm{Cu}$ lines are indicated, whose linewidths are 2 , $4,6,8,10,20$, and $100 \mu \mathrm{m}$, respectively, left to right. Positive and negative signs represent tensile and compressive stresses, respectively.

the strain fields, as observed via the extinction contrast annihilation of the Pendellösung fringes, lies deeper into the substrate with increasing linewidth.

The micro-Raman spectroscopy ( $\mu \mathrm{RS})$ measurements were also carried out on these $500 \mathrm{~nm}$ thick electroless $\mathrm{Cu}$ metallization samples. In the preannealed case the normal stresses $\sigma_{X X}$ measured using $\mu \mathrm{RS}$ for $2,4,6,8,10,20$, and $100 \mu \mathrm{m} \mathrm{Cu}$ linewidths and are illustrated in Fig. 5. It is clear that the stresses imposed in the $\mathrm{Si}$ substrate due to the $\mathrm{Cu}$ metallization are dependent on the $\mathrm{Cu}$ linewidth. The $\mu \mathrm{RS}$ results indicate that the stresses build up near the edge of the metal line. For a comparative analysis, the behavior of the strains in the underlying $\mathrm{Si}$ were observed in a $\sim 0.5 \mu \mathrm{m}$ wide region just outside the edge of the metal lines. This region was selected in order to eliminate the possibility of any interaction of the probe laser with the overlying metallization (e.g., through absorption, etc.). The induced strains tend to be at their greatest magnitude at the material discontinuity represented by the metal edge. If the induced strain in the $\mathrm{Si}$ at the outside of the metal line is tensile, then the region just inside the metal line tends to be under compressive stress, or vice versa. This strain sign reversal was observed for all observed and simulated linewidths in this study.

The relationship between the $\mathrm{Cu}$ linewidth and normal stress $\sigma_{X X}$ in the Si $0.5 \mu \mathrm{m}$ away from the outer edge of the $\mathrm{Cu}$ line is shown in Fig. 6. The normal stresses imposed in the $\mathrm{Si}$ wafer due to the electroless $\mathrm{Cu}$ metallization are com-

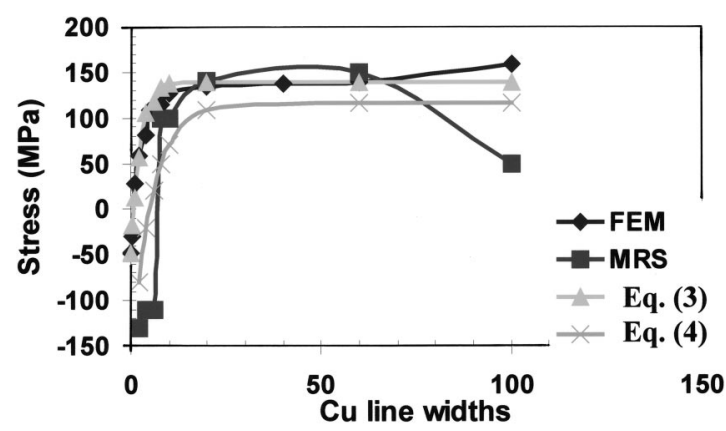

FIG. 6. A comparison of the normal stress in the $X$ direction $\left(\sigma_{X X}\right)$ from experimental $\mu \mathrm{RS}$ data, the FEM simulation, and the empirical estimations of Eqs. (3) and (4). The stress was measured $0.5 \mu \mathrm{m}$ away from the outer edge of the $\mathrm{Cu}$ line. Preannealed sample. Positive and negative signs represent tensile and compressive stresses, respectively. 
pressive near the outer edge of the $\mathrm{Cu}$ lines when the $\mathrm{Cu}$ linewidth is less than $\sim 10 \mu \mathrm{m}$. The normal stress in $\mathrm{Si}$ changes to tensile stress when the $\mathrm{Cu}$ linewidth is larger than $\sim 10 \mu \mathrm{m}$. In addition, when the $\mathrm{Cu}$ linewidth is larger than $\sim 20 \mu \mathrm{m}$, the magnitude of the tensile stress seems to be almost independent of the $\mathrm{Cu}$ linewidth up to a linewidth $L$ $\sim 60 \mu \mathrm{m}$. An empirical estimate of the imposed stress as a function of $\mathrm{Cu}$ linewidth indicates that the stress $\sigma_{X X}$ due to the electroless $\mathrm{Cu}$ metallization is related to the $\mathrm{Cu}$ linewidth in terms of an exponential distribution:

$$
\sigma_{X X}=139.5-195.5 \exp (-\mathrm{Cu} \text { linewidth/2.3 }) \mathrm{MPa},
$$

where $\mathrm{Cu}$ linewidth is given in microns. This result correlates with the FEM simulation, where $\sigma_{X X}$ is given by the qualitatively similar

$$
\sigma_{X X}=115.6-281.4 \exp (-\mathrm{Cu} \text { linewidth/5.5) } \mathrm{MPa} .
$$

A comparison of the normal stress $\sigma_{X X}$ from the experimental $\mu \mathrm{RS}$ data, the calculated FEM distribution and the empirical estimates of Eqs. (3) and (4) is also shown in Fig. 6. This data clearly indicate that the generated stress versus linewidth $L$ tendency is a function of the geometrical arrangement. The $\mu \mathrm{RS}$ data for $60<L<100 \mu \mathrm{m}$ does clearly indicate that the stress imposed on the $\mathrm{Si}$ due to the $\mathrm{Cu}$ metallization decreases more rapidly than predicted as a function of linewidth. This phenomenon could be explained in terms of a self-annealing effect in the $\mathrm{Cu}$ line. ${ }^{22}$ Graham et $a l .{ }^{23}$ found that the copper self-annealing is a function of the copper linewidths in that the smaller $\mathrm{Cu}$ linewidths require a higher activation energy to achieve full recrystallization than the wider ones. In addition, Lagrange et al. ${ }^{24}$ investigated the $\mathrm{Cu}$ self-annealing phenomenon as a function of the $\mathrm{Cu}$ thickness, and found that the self-annealing is slowed down for a thinner $\mathrm{Cu}$ layer due to physical restrictions, while the thicker layer approached the grain size of recrystallized copper, forcing growth to proceed in two dimensions (2D). Therefore, the stress relief tends to be lower when the layer is thinner due to the physical limitation. Brongersma et al. ${ }^{25}$ agrees with Lagrange et al. Nevertheless, Brongersma et al. also mentioned that a very rapid primary crystallization occurred from the top surface down just after deposition, which was then followed by a slower lateral recrystallization producing large secondary grains. The physical limitation of the $\mathrm{Cu}$ lines could explain the self-annealing phenomenon as a function of the $\mathrm{Cu}$ volume in that the recrystallization process could not occur when the $\mathrm{Cu}$ linewidth becomes very small since the density of grains per volume is not large enough for the recrystallization process to occur. Therefore, the stress in $\mathrm{Si}$ due to the small $\mathrm{Cu}$ linewidths is still frozen within, whereas the stress in the $\mathrm{Si}$ due to the wider $\mathrm{Cu}$ metallization is relieved by the self-annealing process. From the $\mu \mathrm{RS}$ and FEM results in Fig. 6, it can be argued that the stress generated in the $\mathrm{Si}$ is mainly due to the geometrical effect without self-annealing at $L<20 \mu \mathrm{m}$, whereas the selfannealing may influence the stress imposed on $\mathrm{Si}$ for $60<L<100 \mu \mathrm{m}$.

To investigate the grain size/density in the copper as a function of the $\mathrm{Cu}$ linewidths due to the self-annealing effect, AFM was performed. A representative selection of AFM re-
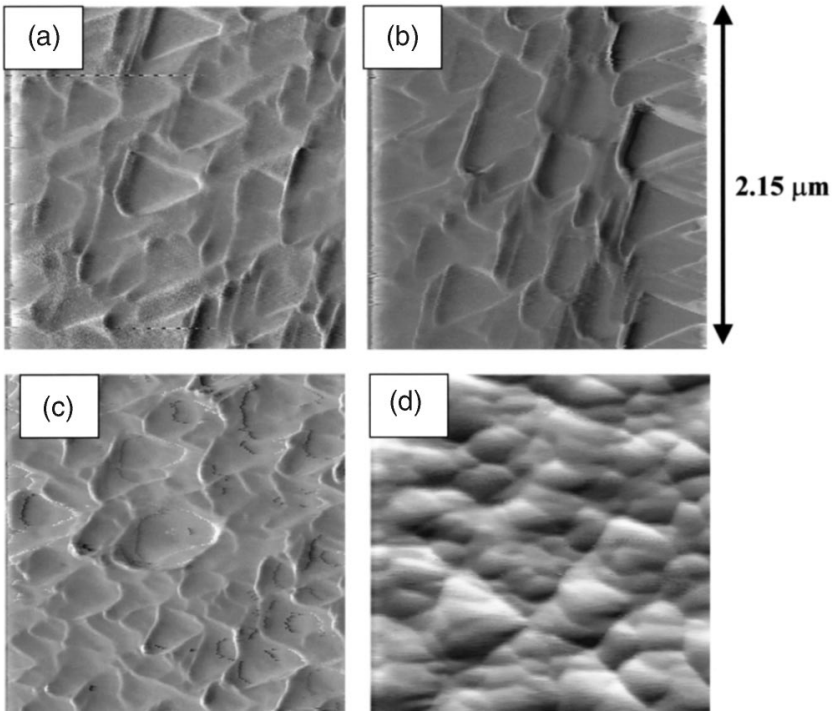

FIG. 7. AFM results for the Preannealed electroless $\mathrm{Cu}$ as a function of the $\mathrm{Cu}$ line widths of (a) $2 \mu \mathrm{m}$, (b) $4 \mu \mathrm{m}$, (c) $60 \mu \mathrm{m}$, and (d) $100 \mu \mathrm{m}$.

sults for $\mathrm{Cu}$ linewidths of 2, 4, 60, and $100 \mu \mathrm{m}$ are illustrated in Figs. 7(a)-7(d), respectively. The AFM images for the other lines with $L=20 \mu \mathrm{m}$ are similar to Fig. 7(a) or 7(b). The AFM results show that the grains within the $\mathrm{Cu}$ lines exhibit (111) faceting (hence the triangular symmetry) and have sizes of about $0.3-0.5 \mu \mathrm{m}$ for linewidths of $2 \mu \mathrm{m}-20 \mu \mathrm{m}$. Thereafter one observes the formation of copper clusters when the $\mathrm{Cu}$ linewidth gets bigger, i.e., $L>60 \mu \mathrm{m}$. This implies that the cluster formation is related to at least a partial relief of stress in the $\mathrm{Cu}$ lines and thus also in the underlying $\mathrm{Si}$. This result correlates with the suggestion that the self-annealing phenomenon influences the stress in Si only when $60<L<100 \mu \mathrm{m}$.

\section{B. Temperature dependence of the strain fields in Si substrate induced by the electroless $\mathrm{Cu}$ metallization process}

To study the temperature dependence of the stress distributions in the $\mathrm{Si}$ wafers induced by the $\mathrm{Cu}$ metallization process, the samples were mounted on a heating stage. The $\mathrm{X}$-ray topographs were then recorded at room temperature $100,200,300$, and $400{ }^{\circ} \mathrm{C}$. The faster Kodak film used in this instance, as any imaging in the presence of small thermal variations in the heating stage, would lead to blurred topographic images on the $\sim 60$ times slower VRP-M film. Large area back reflection topographs are shown in Fig. 8. The strain fields imposed by the metallization in the underlying $\mathrm{Si}$ are observed as the parallel (mostly) black lines, corresponding to enhanced strain regions close to the metal line edges. Although initially weak at room temperatures (i.e., in the as-deposited condition), the images of the strain fields become even more difficult to discern at temperatures approaching $200{ }^{\circ} \mathrm{C}$ [Fig. 2(c)]. This is most likely due to the fact that the strains go through a minimum near this temperature. Thereafter the images of the strain fields for $300{ }^{\circ} \mathrm{C}$ and $400{ }^{\circ} \mathrm{C}$ are much stronger, implying a return to a higher strain regime. Riedel et al. ${ }^{26}$ investigated this phenomenon in $500 \mathrm{~nm}$ thick $\mathrm{Cu}$ film deposited by chemical vapor deposi- 

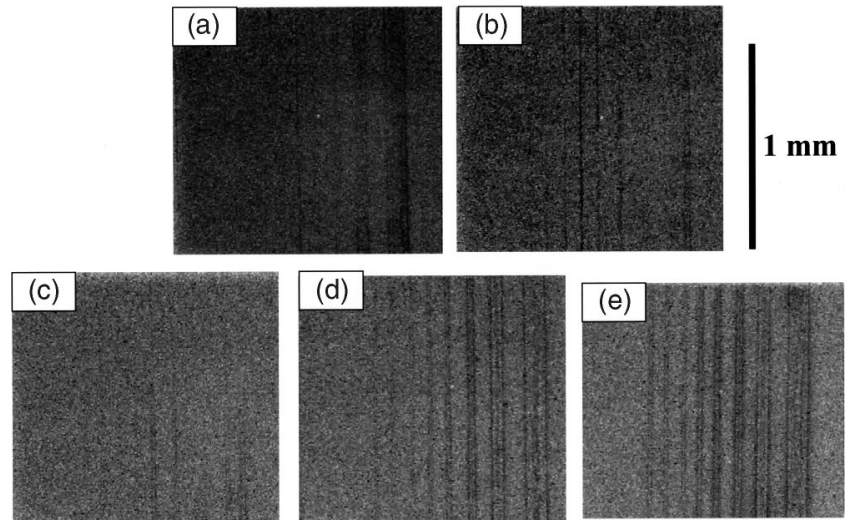

FIG. 8. $\overline{22} 8$ LA-BRT images for the electroless $\mathrm{Cu}$ samples, which have been taken at the following temperatures: (a) room temperature, (b) $100{ }^{\circ} \mathrm{C}$, (c) $200{ }^{\circ} \mathrm{C}$, (d) $300{ }^{\circ} \mathrm{C}$, (e) $400{ }^{\circ} \mathrm{C}$. The projection of the diffraction vector $\mathrm{g}$ on the recording film is also shown.

tion. Although the $\mathrm{Cu}$ was deposited by a different technique, a similar phenomenon was observed wherein the strain proceeded through a zero point as the strain due to the deposited $\mathrm{Cu}$ changed from tensile to compressive during heating. This annealing temperature vs stress transformation phenomenon has been simulated using FEM.

By way of example, we now illustrate the FEM carried out for the $20 \mu \mathrm{m}$ linewidth $\mathrm{Cu}$ metallization, which was annealed at $100,200,300$ and $400{ }^{\circ} \mathrm{C}$. A comparison of the stresses in the $\mathrm{Si}$ wafer for the $\mathrm{Cu}$ metallization before and after annealing along the $\mathrm{Si} /$ metal interface is shown in Fig. 9. The normal stress $\sigma_{X X}$ is only shown here, but the FEM results indicate that the stress distributions in the $\mathrm{Si}$ wafer at the outer edge of the $\mathrm{Cu}$ line are compressive for $\sigma_{X X}$ and $\sigma_{Y Y}$, and tensile for $\tau_{X Y}$ at room temperature. After the sample was heated at elevated temperature from 100 to $400{ }^{\circ} \mathrm{C}$, the stress transformed into the opposite state (i.e., tensile became compressive, and compressive became tensile). This strain-reversal effect was observed in all simulated $\mathrm{Cu}$ linewidths. Although the strain transition point is slightly different, this FEM simulation confirms the correlation of the strain transition phenomenon with the SXRT results of Fig. 8.

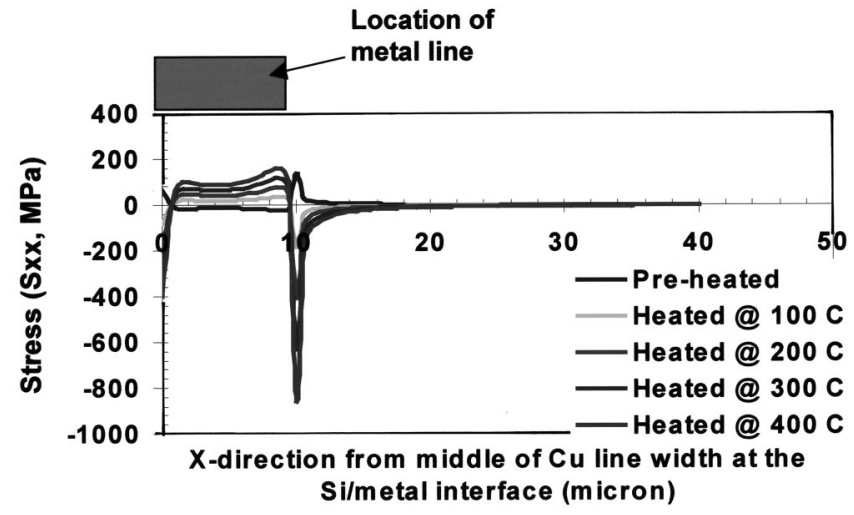

FIG. 9. The FEM simulation of the induced normal strain $S_{X X}$ for the Preannealed and Annealed $20 \mu \mathrm{m}$ wide copper line along the $x$-direction from the middle of the metal line $(X=0 \mu \mathrm{m})$ to the edge of the metal $(X$ $=10 \mu \mathrm{m})$ at the $\mathrm{Si} /$ metal interface $(X=150 \mu \mathrm{m})$. Due to symmetry, only half of the linewidth is simulated.

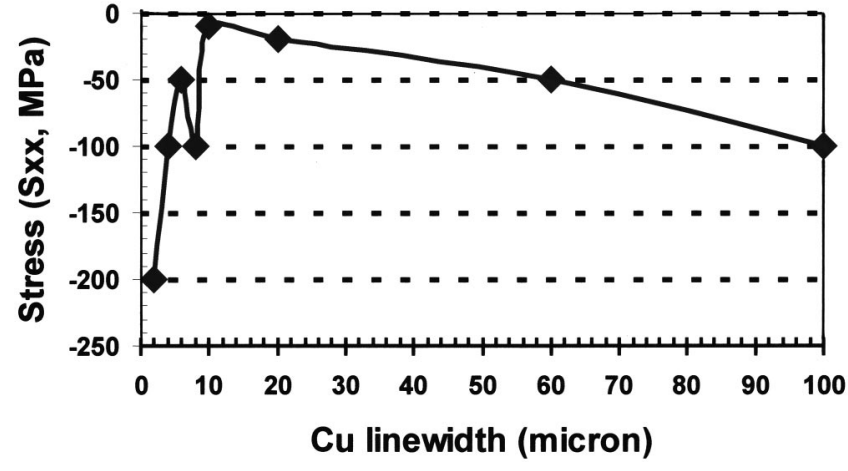

FIG. 10. The measured normal stress $\sigma_{X X}$ in $\mathrm{Si}$ imposed due to the $\mathrm{Cu}$ metallization near the edge of the metal line after annealing at $400{ }^{\circ} \mathrm{C}$ as a function of $\mathrm{Cu}$ linewidth measured $0.5 \mu \mathrm{m}$ outside the outer edge of each $\mathrm{Cu}$ line.

To study the effect of annealing on electroless $\mathrm{Cu}$ metallization as a function of the linewidth, a set of metallized $500 \mathrm{~nm}$ thick electroless $\mathrm{Cu}$ samples were annealed at $400{ }^{\circ} \mathrm{C}$ and measured using $\mu \mathrm{RS}$. The relationship between the $\mathrm{Cu}$ linewidth and normal stress $\sigma_{X X}$ in the Si $0.5 \mu \mathrm{m}$ outside the outer edge of each $\mathrm{Cu}$ line is shown in Fig. 10. In this case, the normal stresses in the Si near the outer edge of the $\mathrm{Cu}$ lines are shifted to the compressive state for the entire range of the $\mathrm{Cu}$ linewidths after annealing. The only exception to this is for the $L=8 \mu \mathrm{m}$ line-the data as shown on Fig. 10 for that point are real and do not represent noise. However, the overall shape of the curve for the relationship of the Annealed sample stress and $\mathrm{Cu}$ linewidth is similar to that for the Preannealed sample (Fig. 6) in that the stresses become more compressive with decreasing $\mathrm{Cu}$ linewidths for linewidths below $\sim 10 \mu \mathrm{m}$. Subsequently, the tendency changes as the normal stresses decrease with increasing $\mathrm{Cu}$ linewidth in the $20-100 \mu \mathrm{m}$ range.

Again, the AFM measurement was performed using the same system and the same settings as previously used to investigate the grain size/density of the $\mathrm{Cu}$ as a function of the annealed $\mathrm{Cu}$ linewidths after annealing at $400{ }^{\circ} \mathrm{C}$. These AFM results show that the grain sizes of the $\mathrm{Cu}$ lines are of a similar tendency to the AFM results of the preannealed case [Figs. 7(a)-7(d)]. In this case, the $\mathrm{Cu}$ grains also show (111) faceting with grain sizes of $0.3-0.35 \mu \mathrm{m}$ for linewidths less than $10 \mu \mathrm{m}$ and thereafter start forming copper clusters with an average grain size of about $0.2 \mu \mathrm{m}$ when the $\mathrm{Cu}$ linewidth gets bigger, i.e., $L>60 \mu \mathrm{m}$. This suggests the stress imposed on the $\mathrm{Si}$ substrate, as a function of the $\mathrm{Cu}$ linewidths, should be about the same if the stress were correlated to $\mathrm{Cu}$ grain size. However, this result does not appear to explain the shift of the stress in the $\mathrm{Si}$ due to the $\mathrm{Cu}$ lines to a compressive state. The shift of the stress imposed on the Si due to the annealing step is possibly due to the thermal mismatch between the $\mathrm{Si}$, the metal layers, and the possibly new intermetallic compounds created in the metal layers at the interface between the barrier film and the $\mathrm{Cu}$ layer.

\section{CONCLUSIONS}

Synchrotron $\mathrm{x}$-ray topography, micro-Raman spectroscopy, finite element modeling, and atomic force microscopy 
have been used to examine the stress regimes imposed in the underlying $\mathrm{Si}$ substrate as a result of electroless $\mathrm{Cu}$ deposition. The SXRT technique showed that the stresses in $\mathrm{Si}$ induced by the electroless $\mathrm{Cu}$ metallization were intense at the edge of the metal lines and were of the order of $100 \mathrm{MPa}$ near the outer edge of the interface between $\mathrm{Si}$ and the $\mathrm{Cu}$ metal layers. This result agrees with the FEM simulations. The SXRT topographs indicated that this stress was mostly relieved by annealing at $200{ }^{\circ} \mathrm{C}$. Although the strain transition point is slightly different from the SXRT result the FEM results confirmed the existence of a zero-strain transition point as a function of thermal anneal.

The stress distributions in $\mathrm{Si}$ as a function of the $\mathrm{Cu}$ linewidth for $2 \leqslant L \leqslant 100 \mu \mathrm{m}$ electroless $\mathrm{Cu}$ lines were investigated. The FEM result is in accordance with the $\mu \mathrm{RS}$ results. For $\mathrm{Cu}$ linewidths less than $20 \mu \mathrm{m}$, the stress increased with a decrease of the $\mathrm{Cu}$ linewidth due to the thermal stress in the absence of self-annealing, whereas the stress decreased with increasing linewidths in the range of $60-100 \mu \mathrm{m}$ due to a relief of the thermal stress possibly via the self-annealing effect. This self-annealing phenomenon was observed using AFM.

The effect of the annealing process on the $\mathrm{Cu}$ metallization was investigated using the $\mu \mathrm{RS}$ and AFM techniques. It was observed that the stresses in the Si shifted to a compressive state after annealing at $400{ }^{\circ} \mathrm{C}$. In addition, the relationship between the stress and the $\mathrm{Cu}$ linewidth of the preannealed sample displays the same tendency as that of the annealed sample.

\section{ACKNOWLEDGMENTS}

This work was supported by the IHP Contract No. HPRICT-2001-00140 of the European Community. The support of T. Wroblewski and C. Paulmann at HASYLAB beamline F-1 and Christophe Frieh at the Topo-beamline, ISS (Institut für Synchrotron-Forschung, Forschungszentrum Karlsruhe) was gratefully acknowledged, and was supported by the IA SFS Contract No. RII3-CT-2004-506008 of the European Commission.
${ }^{1}$ J. R. Lloyd, J. Clemens, and R. Snede, Microelectron. Reliab. 39, 1595 (1999).

${ }^{2}$ P. Singer, Semicond. Int. 1988, 91.

${ }^{3}$ Copper-Fundamental Mechanisms for Microelectronic Applications, edited by S. P. Murarka, I. V. Verner, and R. J. Gutmann (Wiley, New York, 2000).

${ }^{4}$ Multilevel Interconnect Technology, edited by G. K. Rao (McGraw-Hill, New York, 1993).

${ }^{5} \mathrm{P}$. R. Besser, in Stress Induced Phenomena in Metallization, edited by Oliver Kraft, Edward Arzt, Cynthia A. Volkent Paul S. Ho, and Hidekozu Orbay AIP Conf. Proc. No. 491, (AIP, Melville, NY, 1999), p. 229.

${ }^{6}$ J. Kasthurirangan, Y. Du, P. Ho, C. Capasso, M. Gall, D. Jawarani, R. Hernandez, and H. Kawasaki, Stress Induced Phenomena in Metallization, Ref. 5, p. 304.

${ }^{7}$ T. D. Sullivan, in Ref. 5, p. 39.

${ }^{8}$ J. Kanatharana et al., J. Phys. D 36, A60 (2003).

${ }^{9}$ J. Kanatharana et al., Microelectron. Eng. 65, 209 (2003).

${ }^{10}$ Y. Shacham-Diamand, V. Dubin, and M. Angyal, Thin Solid Films 262, 93 (1995).

${ }^{11}$ T. Tuomi, K. Naukkarinen, and P. Rabe, Phys. Status Solidi A 25, 93 (1974).

${ }^{12}$ High Resolution X-ray Diffractometry and Topography, edited by D. K. Bowen and B. K. Tanner (Taylor \& Francis, London, 1998), pp. 189-200.

${ }^{13} \mathrm{X}$-Ray and Neutron Dynamical Diffraction: Theory and Applications, edited by A. Authier, S. Lagomarsino, and B. K. Tanner (Plenum, New York, 1996).

${ }^{14}$ E. S. Meieran and I. A. Blech, J. Appl. Phys. 36, 3162 (1965).

${ }^{15}$ I. A. Blech and E. S. Meieran, J. Appl. Phys. 38, 2913 (1967)

${ }^{16}$ E. S. Meieran and I. A. Blech, J. Appl. Phys. 43, 265 (1972).

${ }^{17}$ E. S. Meieran and I. A. Blech, Phys. Status Solidi 29, 653 (1968).

${ }^{18}$ P. J. McNallyet al., J. Mater. Sci.: Mater. Electron. 10, 351 (1999).

${ }^{19}$ I. De Wolf, J. Raman Spectrosc. 30, 877 (1999).

${ }^{20} \mathrm{http} / / / \mathrm{www}$.quickfield.com

${ }^{21}$ Handbook for Hybrid Microelectronics Materials, edited by J. A. King (Artech, Boston, 1988).

${ }^{22}$ M. Yamada, K. Yoshie, S. Yamaguchi., H. Niwa, M. Hosaka., T. Kouno, Y. Mizushima, N. Misawa, K. Kakuta, T. Suzuki., R. Shinohara., M. Ikeda, H. Kudo, and A. Tsukune, Advanced Metallization Conference in 1998 (AMC 1998), edited by G. S. Sandhuet al., MRS Symposia Proceedings No. 14 (Materials Research Society, Pittsburgh, 1998), p. 19.

${ }^{23}$ L. Graham, T. Ritzdorf, D. Clarke, and R. Thakur, Semicond. Fabtech 11, 270 (1999).

${ }^{24}$ S. L. Lagrange, S. H. Brongersma, M. Judelewicz, A. Saerens, I. Vervoort, E. Richard, R. Palmans, and K. Maex, Microelectron. Eng. 50, 449 (2000).

${ }^{25}$ S. H. Brongersma, E. Richard, I. Vervoort, H. Bender, W. Vandervorst, D. Lagrange, G. Beyer, and K. Maex, J. Appl. Phys. 86, 3642 (1999).

${ }^{26}$ S. Riedel, J. Röber, S. E. Shulz, and T. Gessner, Microelectron. Eng. 37-38, 151 (1997). 